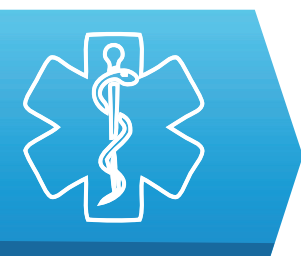

HISTORY OF MEDICINE AND PHARMACY

1) $2^{\text {nd }}$ Department of Internal Medicine, Iuliu Hatieganu University of Medicine and Pharmacy ClujNapoca, Romania

2) Department of Nursing, Iuliu Hatieganu University of Medicine and Pharmacy Cluj-Napoca, Romania

3) Department Psychology, BabesBolyai University Cluj-Napoca, Romania

DOI: $10.15386 /$ cjmed-1245

Manuscript received: 05.11.2018 Accepted: 07.12.2018

Address for correspondence: liliana.david@umfcluj.ro

\section{Is psychosomatic really a bicentennial word? The proof of an older use}

Dan L. Dumitrascu ${ }^{1}$, Liliana David ${ }^{2}$, Adriana Baban ${ }^{3}$

\begin{abstract}
Background and aim. Psychosomatic medicine has different statuses in different countries and many physicians perceive it under various points of view. However, a common belief is that the father of the word psychosomatic is the German physician Johann Heinroth and that the word was coined in 1818. We looked for the history of the word psychosomatic to find out if this information is correct or not.
\end{abstract}

Methods. The available literature was searched online and manually. We recorded available information and looked for other pertinent mentions of this word before 1818 .

Results. Although it is considered that the word psychosomatic is 200 years old, we found evidence that it had been used also in advance. Thus, the history of psychosomatic medicine is even longer. Here is the first report of a scientific work older than 1818. It is a $\mathrm{PhD}$ thesis published in Montpellier in 1784 by Marc Lemort Demétigny.

Conclusions. The general belief is that the first use of the word psychosomatic happened 200 years ago. We found evidence that the word has an older usage.

Keywords: history of medicine, psychosomatic medicine

\section{Introduction}

Psychosomatic medicine is a medical concept defined by the emphasis put on the influence of psychosocial factors on health, as well as on the reciprocal influence between body and mind in health and disease [1]. Psychosomatic medicine has different organization and practice across the world. In some European countries it is a specialty $[2,3]$, in other countries it is not yet organized, in Romania it is an optional teaching curriculum and a master program [4]. Nurses also have access to courses on psychosomatic medicine in this country [5]. The psychosomatic medicine is perceived by many as a kind of psychiatry and many confound it with psychoanalysis or psychotherapy. Psychiatrists have their own psychosomatic approach, called Consultation Liaison (C/L Psychiatry) [6]. The content of behavioral medicine has great overlapping on psychosomatic medicine. The modern approach states that psychosomatic medicine is a paradigm involving the approach of patients (all and not only those with stressinduced conditions). The backbone of psychosomatic medicine is represented by the biopsychosocial model of diseases, elaborated by George Engel [7,8]. Despite the fact that more recently this model has been disputed [9] it is still considered that the biopsychosocial model is superior to the classical biomedical model in the approach of the patients. \section{medicine \\ History of psychosomatic}

The biopsychosocial approach of the suffering human being was practiced in antiquity and in the Oriental Medicine, because it was considered that the mind and the body represent a single entity [5]. This paradigm can be considered holistic. Unfortunately the word holistic is now abused by providers of alternative medicine and by quacks [1].

The philosophy of Rene Descartes [10] contributed to the separated approach of the body and of the mind, considering these two different compounds, according to a mechanistic, reductionist and dualistic approach [11]. The Cartesian conception helped the development of experimental 
medicine but also led in time to the separation of the healthcare provider form the patient. Therefore Descartes ${ }^{6}$ conception was later criticized by some physicians [12].

At present the prevalent conception is that the disease should be approached by giving importance to both body and mind. This approach is perfect for explaining the functional disorders, i.e. those symptoms which cannot be explained in the absence of abnormal organic or biochemical findings.

Although the psychosomatic medical practice is almost as old as the medicine, the word psychosomatic itself has a shorter history.

\section{History of the word psychosomatic}

Several papers report that the first use of the word psychosomatic can be encountered in the book: "Disorders of spiritual life and their therapy " by Johann Heinroth [1315]. It happened in 1818 , thus this word is celebrating now its second centennial.

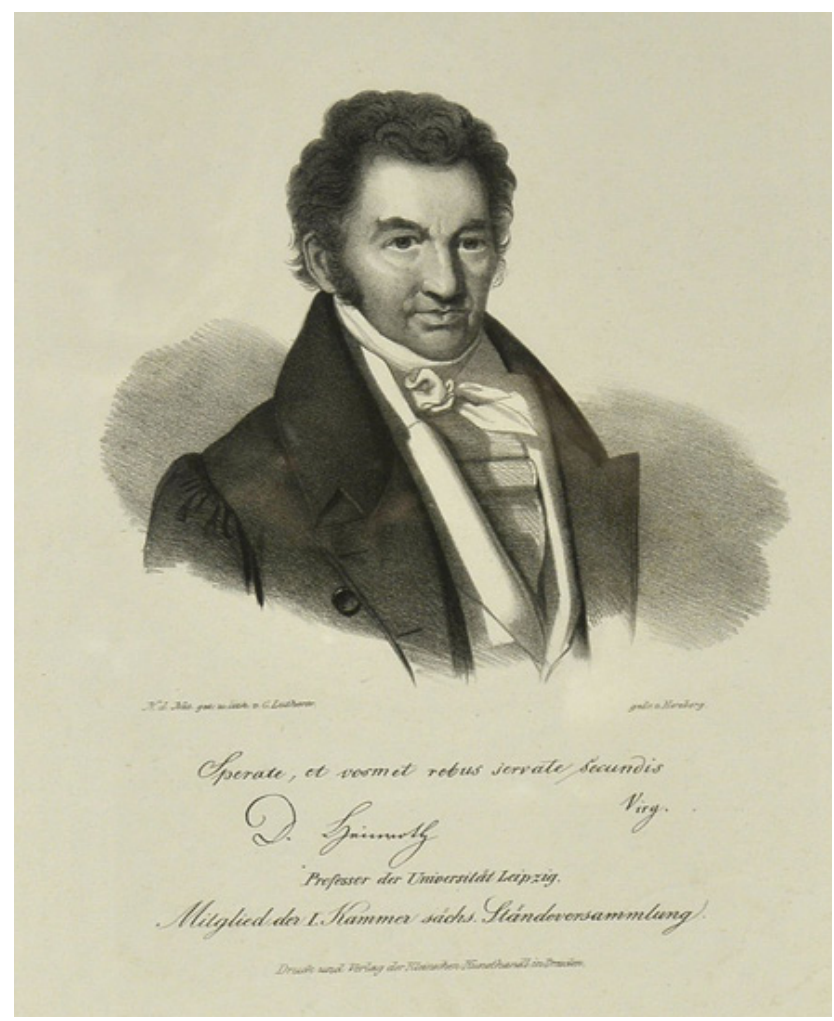

Figure 1. Portrait of Johann Heinroth. Lithograph by CW Lutherer.

Johann Christian Augustus Heinroth (1774-1843) was a son and citizen of the city of Leipzig. Leipizig was one of the most important medical centers in Germany in the era of Biedermaier and the young Heinroth had the best environment for personal and medical environment. Himself the son of a medical doctor, he studied medicine in Leipzig and after several years of medical practice he was appointed professor of psychiatry (called at that time psychic therapy) in 1811 [16]. Beside this, he worked in a psychiatric hospital in Leipzig and soon after his appointment as professor, he organized a sanatorium for mentally ill in Sonnenstein. Till the end of his life, 25 years later, he became an important specialist in psychiatric diseases in Saxony [16].

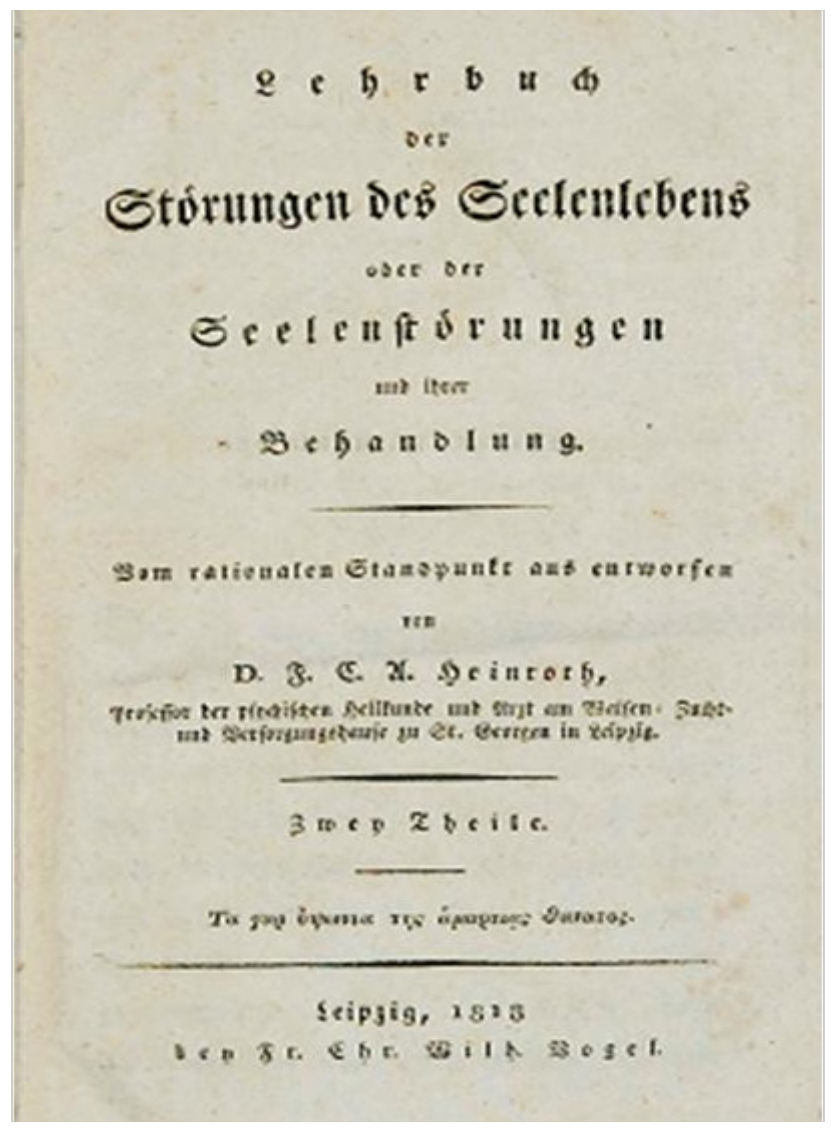

Figure 2. The book where it is considered the word psychosomatic occurred first time. Lehrbuch der Störungen des Seelenlebens oder der Seelenstörungen und ihrer Behandlung. Vogel, Leipzig 1818.

In 1818 he published in two volumes a book of what we call now a textbook of psychiatry. In vernacular language it was called „Lehrbuch der Störungen des Seelenlebens oder der Seelenstörungen und ihrer Behandlung" i.e. "Textbook of disorders of spiritual life and their therapy". The book was published by Vogel Publisher in Leipzig. He emphasized in this work the role of the personality on the onset of the disease and also the role of social risk factors in the occurrence of psychiatric disorders. In this respect he used the word psychosomatic to explain the interference between somatic and mid involvement in disease. In order to improve the mental disease, Heinroth considered that it was mandatory that healthcare providers address to psyhosocial and somatic factors in order to obtain clinical improvement. Here we see now in his book the core of the future psychosomatic medicine. 


\section{New data on the history of the word psychosomatic: it is older}

After an intensive search of literature, not all available on usual data bases, we discovered an older document using the word psychosomatic. This is the book by Marcus (Marc) Lemort Demétigny with the title "Tentamen psycho - somato - iatrikon, seu Conspectus thesiformis De natura animae et corporis, sive de spiritu et materia quatenus medicinam spectant". Thus, the title means: "an essay on psychosomatic medicine". This book was printed in France, in the outstanding of that time medical center of Montpellier, having as publisher Jean-Francois Picot, in 1784. This is a small size book (in quarto), having 50 pages. The cover is in Latin, including also Greek words written in the Greek alphabet, but the content is in French, of course in the archaic language of the time. The format and the size show that this book was a PhD thesis of the epoch. The author considers that both soul and body belong to medicine and explains the function of the soul. We do not know anything about this physician, except he was born in Gand (Ghent) now in Belgium, and studied in Paris.

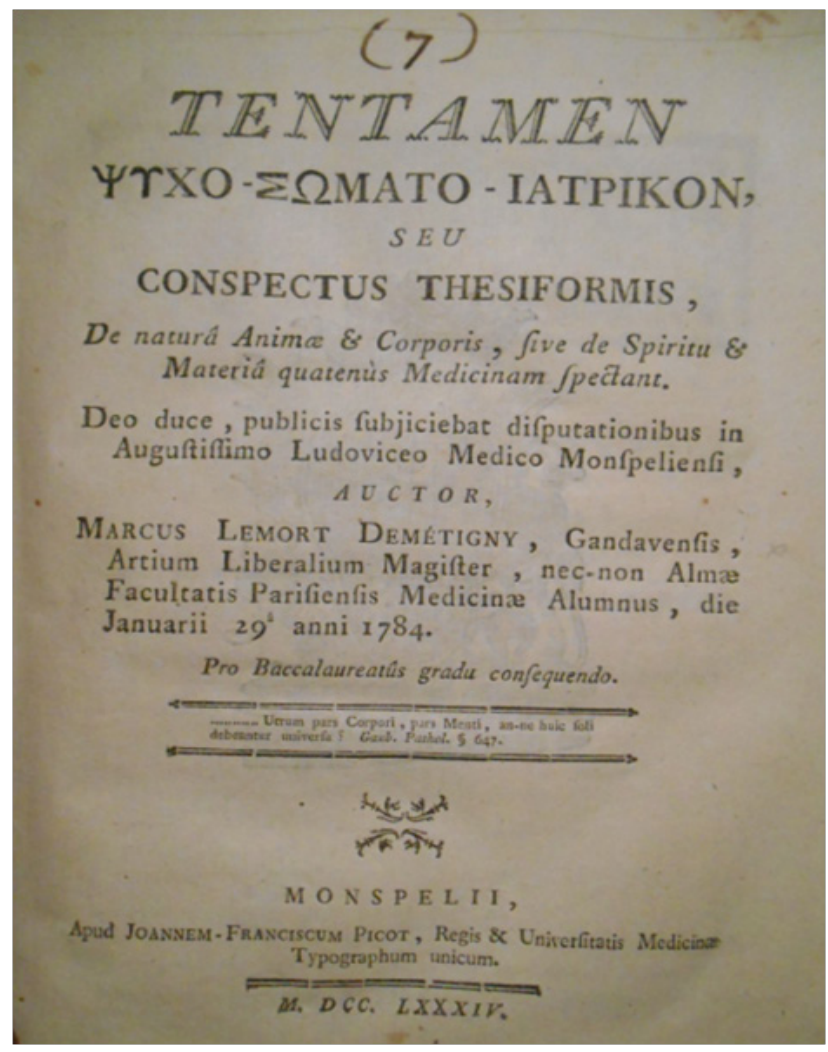

Figure 3. The PhD Thesis of Marc Lemort Demétigny in 1784.

One copy of this book was part of the library of Benjamin Franklin [17]. Another copy is in a private collection in Cluj-Napoca, Romania. We ignore where other copies might still be found, considering that a $\mathrm{PhD}$ thesis was printed in few copies.
To our knowledge this book is the first to explicitly mention the word psychosomatic. It obviously foreruns the book of Heinroth by 34 years and shows that the word psychosomatic is older than 200 years.

Meanwhile we can consider that other books or booklets in different languages and printed in any university center may be discovered in the future.

\section{Conclusions}

There is a common belief that the first documented use of the word psychosomatic is due to Johann Heinroth in 1818. Thus, it is considered that Heinroth is the pioneer of psychosomatic medicine two hundred years ago. We demonstrate here that the word psychosomatic was used 34 years before, in 1784, by Marc Lemort Demétigny. Data about this author are, to our knowledge, still ignored.

\section{References}

1. Dumitrascu D. Psychosomatic medicine. Iuliu Hatieganu Medical University Press, Cluj-Napoca 2014

2. Deter HC. History, concepts and aims of internationally active societies in psychosomatic and behavioural medicine. Biopsychosoc Med. 2016;10:34.

3. Dumitrascu DL, Soellner W. Care and cure. An integrated approach to psychosomatic medicine. Proceedins of the EAPM Annual meeting Sibiu 2014, Ed. MEDIMOND Intern Proc Bologna 2014

4. Dumitrascu DL, Dumitrascu D. Developing psychosomatic medicine in Romania. Psychother Psych Med. 2007;57:190-192.

5. Dumitraşcu DL, David L. Psihosomatică pentru asistente medicale [Psychosomatics for nurses], Ed Med Univ Iuliu Haţieganu Cluj-Napoca, 2008.

6. Leigh, H, Streltzer, J (Eds.) Handbook of Consultation-Liaison Psychiatry, Springer 2015.

7. Engel GL. The need for a new medical model: a challenge for biomedicine. Science. 1977;196:129-136.

8. Engel GL. From biomedical to biopsychosocial. Being scientific in the human domain. Psychosomatics. 1997;38:521-528.

9. Benning TB. Limitations of the biopsychosocial model in psychiatry. Adv Med Educ Pract. 2015;6:347-352.

10. Descartes R. Discourse on the Method. Paperback. SMK Books 2009.

11. Waldstein SR, Neumann SA, Drossman DA, Novack DH. Teaching psychosomatic (biopsychosocial) medicine in United States Medical Schools: survey findings. Psychosom Med. 2001;63:335-343.

12. Damasio A. Descartes' Error. Putnam Publishers, 1994

13. Steinberg H, Herrmann-Lingen C, Himmerich H. Johann Christian August Heinroth: psychosomatic medicine eighty years before Freud. Psychiatr Danub. 2013;25:11-16.

14. Steinberg H. The birth of the word 'psychosomatic' in medical literature by Johann Christian August Heinroth. Fortschr Neurol Psychiatr. 2007;75:413-417.

15. Schneck JM. Psychosomatic medicine. JAMA. 1979;242:2664. 16. Steinberg H: Die Errichtung des ersten psychiatrischen Lehrstuhls: Johann Christian August Heinroth in Leipzig. Der Nervenarzt 2004;75:303-307.

17. Wolf E 2nd, Haynes K: The library of Benjamin Franklin, Amer Philosophical Soc Library Co, Philadelphia 2006. 